\title{
RETROSPECTIVE EVALUATION OF ANESTHESIA EXPERIENCE AT A TRAINING AND RESEARCH HOSPITAL IN TURKEY
}

\author{
Canan YILMAZ ${ }^{1}$, Derya KARASU ${ }^{1}$, Merve Sena BAYTAR ${ }^{1}$, Selim Can YIRTIMCI ${ }^{1}$, Ümran KARACA ${ }^{1}$, Ayşe \\ Neslihan BALKAYA ${ }^{1 *}$, Mehmet GAMLI ${ }^{1}$
}

${ }^{1}$ Health Sciences University Bursa Yuksek Ihtisas Training and Education Hospital Anaesthesiology and Reanimation, 16330, Bursa, Turkey

\begin{abstract}
This study aims to evaluate retrospectively the two-year data of our clinic concerning the effects of training for reduced fresh gas flow anesthesia applications, the demographic data of patients, the types of anesthesia performed, non-operating room anesthesia applications and the incidences of admission to the post-anesthesia care unit. Hospital archives on anesthesia services of 2016-2017 were scanned. The acquired data were analyzed retrospectively with yearly comparisons on the bases of the consumed amount of inhalation anesthetics, distribution of the peripheral blocks according to the surgical sections, the number of patients operated outside the operating room and sent to the post-anesthesia care unit. The number of operations carried out in our hospital was 22533 in 2016 and 24634 in 2017. High flow anesthesia in 2016 and low flow anesthesia in 2017 were found statistically high (P < 0.001). In 2016 and 2017, neuraxial block cases were used in $76.24 \%$ and $76.19 \%$ of the cesarean section, 4936 and 7152 patients underwent anesthesia outside of the operating room; 405 and 816 patients were sent to the post-anesthesia care unit, respectively. In 2017, the consumption of inhalation agents decreased after regular training on the reduced fresh gas flow technique. In 2017, the increase observed in peripheral block applications was based on the increase in ultrasound experience in our clinic. We recom mend a combination of reduced fresh gas flow with peripheral or neuraxial blocks to achieve multimodal general anesthesia.
\end{abstract}

Keywords: General anesthesia, Low flow anesthesia, Inhalation anesthetics, Regional anesthesia, Nerve block

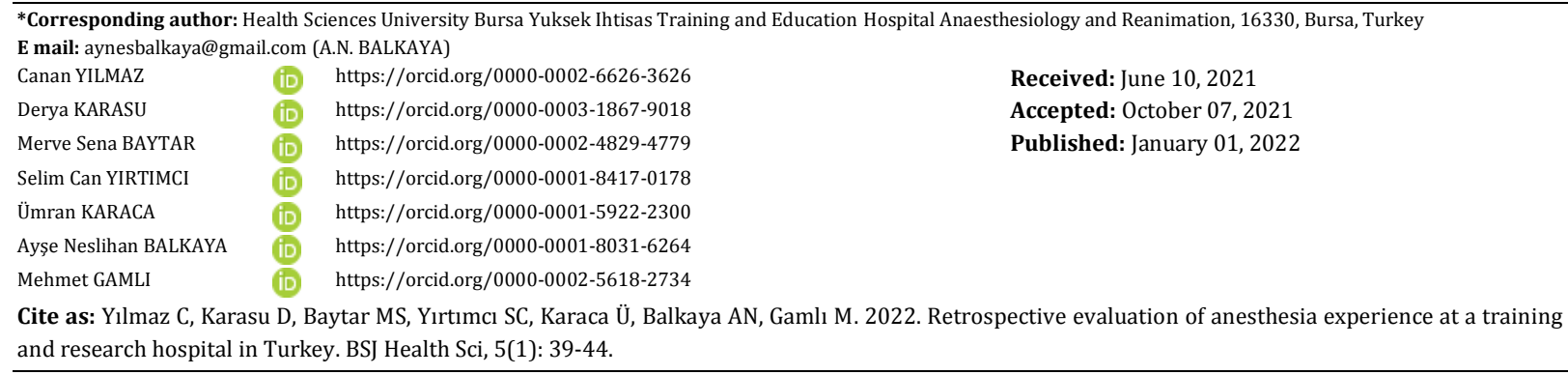

\section{Introduction}

The choice of anesthesia application depends on the type of surgery, the specific condition of the patient, the available types of equipment and the level of accumulated experience in anesthesiology. The age and gender of the patient, the type of the intervention and its duration and the scoring by the American Society of Anesthesiologists (ASA) determine the method of anesthesia to be used and are significant in foreseeing the complications related to anesthesia and the incidence of morbidity and mortality. Therefore, the method of anesthesia should be planned on the type and the duration of the surgery, the characteristics of the patient, the available types of equipment, and the relevant advantages and disadvantages of the technique to be used (Brown et al., 2018). Many advantages have been seen in the use of reduced flow (0.35-1.0 L/min) anesthesia, including mainly the reductions in anesthetic agent consumption, contamination of the operation theatre, cost of surgery and protection of the atmosphere and the global eco-system from harmful gases (Ishizawa, 2011; Brattwall et al., 2012; Horwitz and Jakobsson, 2016). However, the potential risks of hypoxia and carbon monoxide intoxications should be well known. Regular training sessions for reduced flow anesthesia are important in being effective for increasing the critical knowledge on the technique as well as the prevalence of its application.

Anesthesia management takes place both in and outside the operation theatre. The non-operating room anesthesia (NORA) has been increasing in recent years due to the advances in technology that aids the branch of anesthetics (İyilikçi et al., 2006). Pediatric and adult patients of radiology, cardiology, cardiovascular surgery, gastroenterology and psychiatry clinics are being performed when NORA service is given.

In recent years the total and the risky surgery cases are undertaken by the anesthetists of Bursa Yuksek Ihtisas Training and Research Hospital (BYIETH)Anaesthesiology Clinic has risen significantly. In reference to the Ministry of Health records of January- 
October 2017 on the grouped counts of the performed surgical operations, our hospital was ranked as the first in Turkey with 5042 A group surgery cases, the 20th with 6180 B group surgeries, the 24th with $9570 \mathrm{C}$ group surgeries and the 10th with a total of $20792 \mathrm{~A}+\mathrm{B}+\mathrm{C}$ group of surgeries (KHGM, 2017).

In this study, the primary aim was to evaluate the effects of the regular training given by our clinic in reduced flow anesthesia technique on the quality of our performance in anesthesia management in 2017. The secondary aim was to assess the demographic data on the patients, the types of anesthesia used and the incidences of referrals to the postoperative anesthesia care unit (PACU), hospital bed allocation and NORA.

\section{Material and Methods}

After obtaining the Ethics Committee approval (No: 2011-KAEK-25 of 2018/03-12), the data on anesthesia applications in 2016-2017 at were BYIETH acquired from the observations archive and the database of the hospital. A total of 59255 case data, including 47167 operations and 12088 NORA cases were scanned. Patients with incomplete data were excluded from the evaluations. The evaluations included the demographic patient data, the annual distribution of the data on anesthesia techniques and airway management. The anesthesia management in cesarian section cases was evaluated separately. The bottles of anesthetic gas used each year were compared. Intraoperative complications and the complications observed in the PACU were investigated. The number of patients sent to the PACU and the number of mortalities was determined.

The anesthesia methods used in surgeries were noted down in three groups as general anesthesia (GA), regional anesthesia (RA) and peripheral blocks. RA consisted of spinal anesthesia (SA), epidural anesthesia (EA) and combined spinal and epidural anesthesia (CSE). Peripheral nerve block grouping included the upper extremity (interscalene, supraclavicular, infraclavicular, axillary, suprascapular) blocks, lower extremity (psoas, sciatic, femoral, adductor canal, genicular, popliteal) blocks, abdominal (classical and subcostal transverse abdominis plane (TAP) block, quadratus lumborum (1-23 , rectus abdominis, ilioinguinal and iliohypogastric) blocks and the thoracal (paravertebral, serratus anterior, pectoral 1-2) blocks. Distribution of the nerve blocks applied each year and in each surgical unit were compared.

The SPSS 22 Windows program (Statistical Package for Social Sciences, Armonk, NY, USA) was used for the statistical analysis. Statistical analysis results for the categorical data were expressed in numbers and percentages. The Chi-square tests were used in the analysis of data that did not comply with the normal distribution. P level of $<0.05$ was considered statistically significant.

\section{Results}

Bursa Yuksek Ihtisas Education and Training Hospital consists of 5 buildings housing 31 operation theatres, and 3 PACU beds. In the number Education $r$ of surgical interventions performed in 2016 and 2017 were, respectively, 22533 and 24634, totaling 47167; and the respective number of patients operated in 2016 and 2017 were 11013 and 13104. The majority of the patients were aged within the 18-49 year range, and most frequently had an ASA II score. The demographic data are given in (Table1).

Table 1. Characteristics of patients (n, \%)

\begin{tabular}{lcc}
\hline & 2016 & 2017 \\
& $\mathrm{n}=22533$ & $\mathrm{n}=24634$ \\
\hline Age (y), & & \\
$(\%)$ & $651(2.89 \%)$ & $543(2.21 \%)$ \\
$0-1$ & $1623(7.21 \%)$ & $1654(6.71 \%)$ \\
$1-7$ & $1603(7.11 \%)$ & $1512(6.14 \%)$ \\
$8-17$ & $11013(48.87 \%)$ & $13104(53.19 \%)$ \\
$18-49$ & $6406(28.43 \%)$ & $6591(26.76 \%)$ \\
$50-74$ & $1237(5.49 \%)$ & $1230(4.99 \%)$ \\
$>74$ & & \\
Gender, $\mathrm{n}$ & & \\
$(\%)$ & $10168(45.12 \%)$ & $12182(49.45 \%)$ \\
Male & $12365(54.88 \%)$ & $12452(49.55 \%)$ \\
Female & & \\
ASA, n (\%) & & \\
I & $7644(33.92 \%)$ & $5475(22.23 \%)$ \\
II & $12193(54.10 \%)$ & $15762(63.97 \%)$ \\
III & $2090(9.28 \%)$ & $2598(10.55 \%)$ \\
IV & $567(2.52 \%)$ & $753(3.06 \%)$ \\
V & $32(0.14 \%)$ & $35(0.14 \%)$ \\
VI & $7(0.04 \%)$ & $12(0.05 \%)$ \\
\hline ASA American & &
\end{tabular}

$\mathrm{ASA}=$ American society of Anesthesiologists, $\mathrm{y}=$ year.

The types of anesthesia applied are summarised in Table 2. The most frequent approach in airway management was intubation followed by the use of supraglottic airway devices. In 2016, 81 tubes with double lumen design and 1253 I-gel $^{\text {TM }}$ laryngeal masks (IntersurgicalLtd, Wokingham, UK) were used in 2263 patients; and in 2017, 147 double-lumen tubes and 566 I-gel $^{\mathrm{TM}}$ laryngeal mask airways (Intersurgica lLtd, Wokingham, UK) were used, 2457 patients.

High flow anesthesia in 2016 and low flow anesthesia in 2017 were found statistically high when comparing to the other type of general anesthesia (Figure 1, $\mathrm{P}=0.000$ ). The number of bottles of sevoflurane and desflurane used was, respectively, 1473 and 1115 in 2016 as compared to 1104 and 569 bottles, respectively in 2017 . The cost of inhalation anesthetic agents was 572385.00 TL (Turkish Lira) in 2016 and 353171.00 TL in 2017.

In $2016,23.76 \%(n=1077)$ of the cesarian sections were made under GA, and $76.24 \%(n=3456)$ were made under central blocks. The respective numbers in 2017 were 23.81\% $(n=1187)$ for GA and 76.19\% $(n=3799)$ for 
central block applications (Figure 2). In 2016 and 2017, the numbers of cases with Cormack-Lehane Scores III-IV, or difficult laryngoscopy, were 75 and 62, respectively, and there were not any cases with difficult intubation.

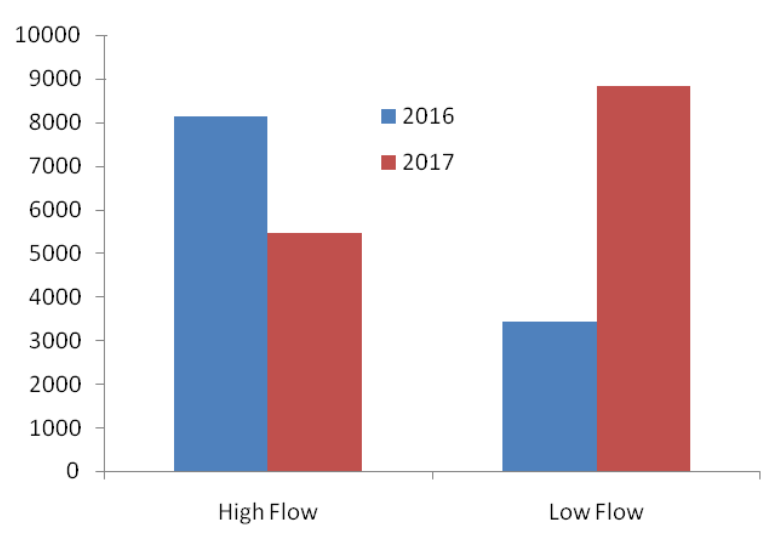

Figure 1. Comparison of low flow and high flow anesthesia in 2016 and 2017.

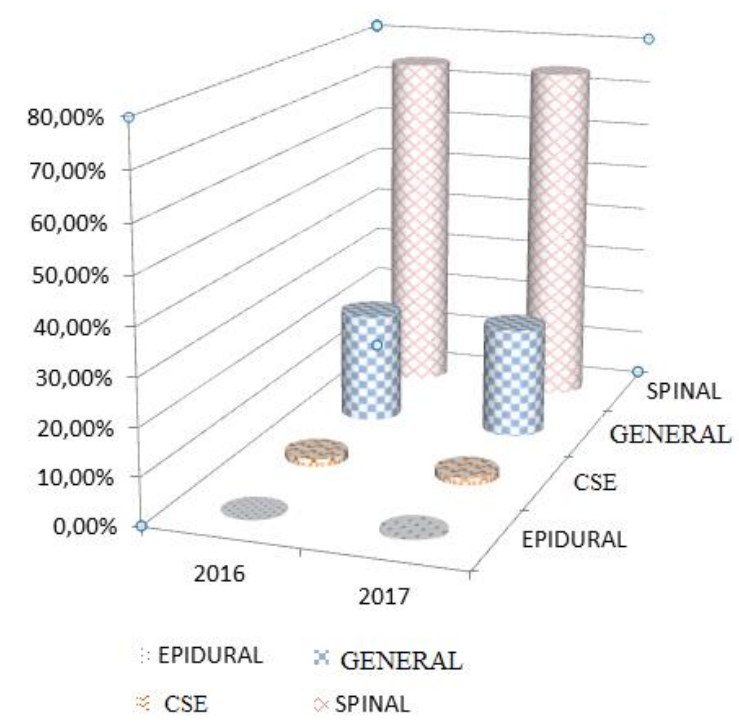

Figure 2. Anesthesia management in cesarean section. $\mathrm{CSE}=$ combined spinal-epidural anesthesia.
With the increased frequency of ultrasonographic applications in our clinic, the themes of the theses presented in 2017 by the students preparing for specialization in anaesthesiology were more frequently on peripheral nerve blocking. Whereas peripheral upper extremity nerve blocks were highly prevalent in 2016, in 2017 the most frequent applications were the abdominal blocks. (Table 3).

Complications that occurred intraoperatively and in the recovery room are given in Table 4 . The most frequently observed complication was hypotension. Local anesthesia intoxication was not observed in any of the patients. Intraoperative cardiac arrest cases increased by 2.5 fold in 2017 as compared to 2016. Hypothermia was the most frequently observed complication in the recovery room followed by hypertension and pain.

In both 2016 and 2017, the majority of patients referred to the PACU were from the brain surgery unit (Table 5). In 2016 , the total number of mortality cases $(n=37)$ was associated with brain surgery $(n=17)$, general surgery $(n=7)$, orthopaedics $(n=5)$, urology $(n=4)$, obstetrics and gynaecology $(n=4)$, while in 2017 the total number of mortality cases $(n=70)$ were again associated most frequently with brain surgery $(n=37)$, followed by orthopaedics ( $n=11)$, urology (8), general surgery $(n=7)$, obstetrics and gynaecology $(n=5)$ and thoracic surgery $(n=2)$. In 2017 the number of patients referred to the PACU nearly doubled but the mortality incidences were equal, being $10.54 \%$ in 2016 and $9.04 \%$ in 2017.

In BPTRH routine MRI (magnetic resonance imaging) service is given on 1 day per week; endoscopy consisting of endoscopic retrograde cholangiopancreatography (ERCP), gastroscopy, and colonoscopy, are performed each day in 3 rooms; 2-3 cardiac interventions including endovascular aneurysm repair (EVAR), thoracic endovascular aneurysm repair (TEVAR)and transcatheter aortic valve implantation (TAVI)are made every week; and NORA service is given for electroconvulsive therapy (ECT) 2-3 days per week.

Table 3. Peripheral Nerve Blocks (n)

\begin{tabular}{|c|c|c|c|c|c|c|c|c|}
\hline \multirow[b]{2}{*}{$\begin{array}{l}\text { Peripheral Nerve } \\
\text { Blocks }\end{array}$} & \multicolumn{4}{|c|}{2016} & \multicolumn{3}{|c|}{2017} & \multirow[b]{2}{*}{ 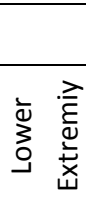 } \\
\hline & $\begin{array}{l}\frac{U}{U} \\
\frac{\pi}{0} \\
\frac{0}{F} \\
\end{array}$ & 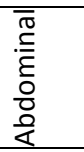 & 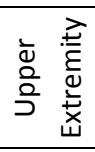 & 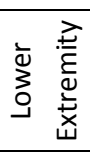 & $\begin{array}{l}\frac{U}{U} \\
\frac{\pi}{0} \\
\frac{0}{F}\end{array}$ & $\begin{array}{l}\bar{\pi} \\
\stackrel{5}{\bar{\varepsilon}} \\
\frac{0}{0} \\
\frac{0}{\alpha} \\
\end{array}$ & 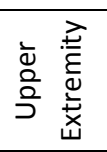 & \\
\hline General Surgery & 1 & 232 & - & - & 1 & 268 & - & - \\
\hline Orthopedics & 8 & 4 & 263 & 198 & 23 & 12 & 246 & 176 \\
\hline Urology & - & 42 & - & - & - & 167 & - & - \\
\hline Obstetrics and & - & 47 & & - & - & 519 & 0 & - \\
\hline \multicolumn{9}{|l|}{ Gynecology } \\
\hline Pediatric Surgery & - & 8 & - & - & - & 20 & - & - \\
\hline Thoracic Surgery & 26 & - & - & - & 42 & - & - & - \\
\hline Plastic Surgery & 5 & 8 & 135 & 86 & 7 & 4 & 154 & 7 \\
\hline Others* & 2 & - & 44 & 24 & 2 & - & 72 & 14 \\
\hline TOTAL & 42 & 351 & 442 & 308 & 75 & 990 & 472 & 277 \\
\hline
\end{tabular}




\section{Black Sea Journal of Health Science}

Table 4. Intraoperative and recovery room complications (n)

\begin{tabular}{lcc}
\hline Intraoperative(n) & 2016 & 2017 \\
\hline Hypotension & 3011 & 3156 \\
Hypertension & 1855 & 1802 \\
Arhythmia & 705 & 672 \\
Nausea and Vomiting & 458 & 504 \\
Failed regional anesthesia & 116 & 84 \\
Allergic reaction & 36 & 26 \\
Difficult intubation & 98 & 58 \\
Bronchospasm & 78 & 96 \\
Cardiac arrest & 11 & 28 \\
Tooth damage & 5 & 7 \\
\hline
\end{tabular}

Table 5. Number of patients transfer to PACU (n)

\begin{tabular}{lcc}
\hline & $2016 \mathrm{n}=351$ & $2017 \mathrm{n}=774$ \\
\hline Orthopedics & 54 & 156 \\
Neurosurgery & 125 & 276 \\
Urology & 76 & 204 \\
General Surgery & 12 & 23 \\
Thoracic Surgery & 12 & 28 \\
Otorhinolaryngology & 18 & 27 \\
Obstetrics and Gynecology & 54 & 60 \\
\hline
\end{tabular}

PACU= postoperative anesthesia care unit.

In 2016 endoscopy, MRI and ECT were performed with NORA service on 4360, 469 and 93 patients, respectively. In 2017 endoscopy, MRI and ECT were performed with NORA service on, respectively, 5759, 596 and 738 patients. In 2016 and 2017, respectively, 7 and 8 patients were referred to PACU. In 2016 and 2017, cardiac interventions with NORA were given to 14 and 59 patients, respectively, when 2 patients in 2016 and 5 patients in 2017 received GA while the rest were operated under sedation. All cardiac intervention patients were placed in the cardiovascular surgery and cardiology intensive care unit for close observation.

\section{Discussion}

The operations performed at the BYIETH numbered 22610 in 2016 and 24771in 2017, totaling 47381. In both of these years, patients with 18-49 years of age and ASA II were in majority. In 2016 and 2017, respectively, $58.19 \%$ and $61.57 \%$ of the patients undergoing surgery were given GA. In the anesthesia clinic, education was given in two programs to the trainee anesthetics specialists and the research staff and in four programs to the technical staff in 2017 to raise their expertise and awareness in the application of reduced gas flow anesthesia. As a result, it was found that 1473 bottles of sevoflurane and 1115 bottles of desflurane consumed in 2016 were reduced to, respectively 1104 and 569 bottles in 2017. In cesarian section cases, the central block was applied to $76.24 \%$ and $76.19 \%$ of the patients in, respectively 2016 and 2017. Upper extremity peripheral nerve blocks were predominant in 2016, but abdominal nerve blocks were the most frequently applied peripheral blocks in 2017. The most frequently met complications consisted of intraoperative hypotension and recovery room hypothermia. In both 2016 and 2017, the majority of the patients referred to the PACU were brain surgery cases, and although all referrals to the PACU were doubled in numbers in 2017, the incidences of mortality remained very similar. Endoscopy, MR, ECT and cardiac interventions in 2016 were performed on, respectively, 4360, 469, 93 and 14 patients; and in 2017 the respective number of patients were 5759, 596, 738 and 59 when the patients were given NORA service.

Reduced fresh gas flow anesthesia is described as the return of at least $50 \%$ of the exhaled gases back to the lungs after $\mathrm{CO}_{2}$ absorption in a rebreathing system. In recent years, reduced fresh gas flow applications in cases requiring anesthesia have been increasing (Odin and Feiss, 2005). When applied with suitable monitoring and respiratory devices, reduced flow anesthesia provides distinct advantages by reductions in anesthetic gas consumption, costs, environmental pollution as well as proper humidification and warming up of the anesthetic gases. Comparison of the reduced flow and the minimal flow anesthesia on the consumption of inhalation agents showed that minimal flow reduced desflurane use by $30 \%$ and sevoflurane use by $19 \%$ (Horwitz and Jakobsson, 2016). In our clinic in 2016, the total sevoflurane and desflurane were used, respectively, in $11.23 \%$ and $8.50 \%$ of the 13112 patients, while these figures were, respectively, $7.27 \%$ and $3.75 \%$ of the 15169 patients in 2017, such that, in comparison to 2016, the savings in sevoflurane and desflurane consumptions were computed to be, respectively, $35.27 \%$ and $55.89 \%$. Whereas 1-4 L of fresh gas was used in 2016, this was maximally $2 \mathrm{~L}$, but mostly in the $0.25-1 \mathrm{~L}$ range with the reduced fresh gas flow applications in 2017. Educational programs on the use of reduced flow gas anesthesia were given with regularity in 2 sessions to the post-graduate anesthesia trainees and the research staff, and in 4 sessions to the technical staff. Education on this subject and preparation of protocols were effective in reducing the inhalant anesthetic agent use (Okur et al., 2016; Hancl et al., 2010). In 2017, the reduced fresh gas flow technique was widely used in our operating theatre as a result of this training program. It was reported by Amma et al. (2016) that $73.8 \%$ of the 164 Indian anesthetists, routinely used the reduced fresh gas flow technique. We believe in line with Horowitz et al. that significant decrease in the consumption of anesthetic inhalation agents used in our work depends on not using the high flow gas method, restricting the use of the metabolic flow to the cases necessitating it and the regularity of training programs in the clinic (Horwitz and Jakobsson, 2016). Hence, significant contributions were made to the comfortable recovery of the patient from anesthesia and the reduction of the hospital cost burden.

Regional anesthesia has important advantages in allowing consciousness, a continuation of spontaneous 
breathing, postoperative pain control, and early mobilization. Peripheral nerve blocks are preferred in having low side effects on attaining the required surgical anesthesia level and facilitating postoperative analgesia. In recent years, reduction of the anesthetic agent doses by adding adjuvant agents and the simultaneous use of nerve stimulators and ultrasonography have increased the reliability of the peripheral nerve block method. The low dosage of the anesthetic agents used when resorting to central blocks or peripheral blocks in addition to GA, especially with geriatric and chronically ill patients with high ASA scores, reduces the risk of complications and provides long term postoperative analgesia. In our clinic, peripheral nerve blocks are frequently used primarily in obstetrics and gynecology, orthopedics, urology, plastic, and general surgery theatres. Various peripheral nerve blocks were used on1143 patients in 2016 and on 1814 patients in 2017. Ultrasonography courses were organized in our clinic after the availability of ultrasonography in the second half of 2016 when 2 devices were put to use in our theatres. In 2017, multiple research works were undertaken and also 5 trainee anesthesia specialists prepared theses on the topic of ultrasonography-guided nerve blocks. As a result of these works, an increase in the use of especially the truncal blocks was observed in our clinic.

In cesarian section cases, pregnancy-related increase in the incidence of the difficult airway during GA makes RA the preferred approach since the mother is awake and able to make immediate contact with her newborn, who is not affected by the passage of anesthetic agents, while effective postoperative analgesia is provided. Regional is reliably applied by specialists trained for anesthesia in obstetrics (Töre et al., 2009). Complications under GA exceed those met during RA (Lai et al., 2014; Ahmad and Afshan, 2011) and the approach is becoming more prevalent in the USA and Europe. After 2002 using RA techniques has increased in Germany and the most frequent applications (90.8\%) were in cesarian section cases (Marcus et al., 2011). Similarly, in Spain, RA is used in $98 \%$ of the cesarian section cases while spinal anesthesia is used in $75 \%$ of the patients (Jenkins and Khan, 2003). RA is also preferred in cesarian section interventions in Norway (95\%), Sweden (90\%), the U.K. (90\%) and the USA (72\%) (Sabate et al., 2006; Palmer, 2009). In Turkey, RA use for cesarian sections varies in the wide range of 30-77\% (Toker et al., 2013; Dağli and Dağll, 2015). In our hospital, RA has been applied in 76\% of cesarian sections cases which is above the mean incidence in the whole of Turkey. Systemic toxicity of local anesthetics was not observed in any of the patients given RA in our hospital.

The anesthesia methods used and the related incidences of complications increase hospital stay and costs (Odin and Feiss, 2005). Our data of 2016 and 2017 indicate that approximately $39 \%$ of all surgical intervention cases and $76 \%$ of the cesarian section cases were anesthetized by RA methods.
To ensure the maintenance of low hospital expenditure, reduced fresh gas flow anesthesia was preferred in patients incompatible with the central block, in agreement with the relevant literature (Gonano et al., 2006; Brown et al., 2018). In our clinic, the combined use of reduced fresh gas flow anesthesia and peripheral blocks are planned to ensure comfort and early mobilization of the patients. This results in the increased numbers and the variety of RA approaches in our clinic.

PACU was established to meet the need for a specialized unit for close monitoring in the critical postoperative period when morbidity and mortality are most frequently observed (Hancl and Pişkin, 2011). The increasing need for PACU has paralleled the development of complicated surgical interventions made possible by the advances in surgery and anesthesia and also by the increased mean patient age with related diseases (Morgan et al., 2002; McGoldrick, 2008). Our study has shown that although the need for PACU had increased in 2017 in comparison to 2016, mortality incidences had remained unchanged.

In recent years increasing preference for minimally invasive surgery to reduce hospital care expenses has led to increased applications of NORA. This requires suitable and adequate monitoring for patient safety and efforts should be made for the availability of the basic anesthesia equipment (TARD, 2015). There have been noteworthy increases in our hospital in the provisions of recovery rooms. For example, one recovery room has been allocated to the pediatric MRI service equipped with MR compatible respiratory and pulse/oximeter anesthesia equipment. There have been increases also in the number of recovery rooms for ECT and endoscopy units which have led to increased applications of NORA. Although the ASA scores of patients given NORA have been increasing, we believe that the increasingly reliable NORA facilities and applications underlie the maintenance of low incidence $(0.12 \%)$ for PACU requirements.

The most important limitation of our study is being retrospective and covering only two years. The Ministry of Health's surgical intervention data inventory for 2016 could not be reached which has prevented the comparison of the counts of the surgical interventions between 2016 and 2017. However, having been given, among other hospitals in Turkey, the first rank in the performance of a group of surgeries in 2017 should point to the importance of our data. Not being able to reach the required data in the entire duration of hospital stay and the incidences of mortality, which have not been documented in an electronic medium, is another limitation of this study.

\section{Conclusion}

In 2017, increased application of especially the truncal blocks among the peripheral blocks has been attributed to the increased expertise in the application of ultrasonography and the research theses contributed by 
the postgraduate trainees in anesthesia. With the increased use of ultrasonography in the risky group of patients with raised ASA scores, peripheral blocks should be given preference. The reduction in the consumption of inhalation agents in 2017 was made possible by the regulated training programs in our clinic, enabling the widespread use of the reduced fresh gas flow technique supplemented with peripheral or central blocks. In conclusion, we recommend multimodal general anesthesia or the use of reduced fresh gas flow in cases requiring GA, supplemented with central or peripheral blocks to provide analgesia. We see the need for studies with a wider scope that cover data on the mean hospital stay, surgical wound infection, and complications encountered in the PACU.

\section{Author Contributions}

CY, DK, MG concept, CK, DK, MG design, supervision, data collection and/or processing, MSB, SCY, ANB and ÜK materials, ÜK, CY, MSB and ANB data analysis and/or interpretation, ÜK, ANB, SCY, MSB and CY literature search and writing.

\section{Conflict of Interest}

The author declared that there is no conflict of interest.

\section{Ethical Approval/Informed Consent}

Ethics approval was obtained from Health Sciences University with decision No: 2011-KAEK-25 and dated 2018/03-12.

\section{References}

Ahmad I, Afshan G. 2011. Knowledge and attitudes of Pakistani women to wards anaesthesia techniques for caesarean section. J Pak Med Assoc, 61(4): 359-362.

Amma RO, Ravindran S, Koshy RC, Jagathnath Krishna KM. 2016. A survey on the use of low flow anaesthesia and the choice of inhalational anaesthetic agents among anaesthesiologists of India. Indian J Anaesth, 60(10): 751756.

Brattwall M, Warrén-Stomberg M, Hesselvik F, Jakobsson J. 2012. Brief review: theory and practice of minimal fresh gas flow anesthesia. Can J Anaesth, 59(8): 785-797.

Brown EN, Pavone KJ, Naranjo M. 2018. Multimodal general anesthesia: theory and practice. Anesth Analg, 127(5): 12461258.

Dağlı R, Dağlı SS. 2015. Anaesthetic method preference of obstetricians for caesarean section. Turk J Anaesthesiol Reanim, 43(1): 41-46.

Gonano C, Leitgeb U, Sitzwohl C, Ihra G, Weinstabl C, Kettner SC. 2006. Spinal versus general anesthesia for orthopedic surgery: anesthesia drug and supply costs. Anesth Analg, 102(2): 524-529.

Hanci V, Pişkin Ö. 2011. Geriatrik anestezide derlenme ve postoperatif bakım. Turkiye Klinikleri J Anest Reanim, 4(1): 52-59.

Hanci V, Yurtlu S, Ayoğlu H. 2010. Effect of low-flow anesthesia education on knowledge, attitude and behavior of the anesthesia team. Kaohsiung J Med Sci, 26(8): 415-421.

Horwitz M, Jakobsson JG. 2016. Desflurane and sevoflurane use during low- and minimal-flow anesthesia at fixed vaporizer settings. Minerva Anestesiologica, 82(2): 180-185.

Ishizawa Y. 2011. Special article: general anesthetic gases and the global environment. Anesth Analg, 112(1): 213-217.

İyilikçi L, Çakmak Ş, Ögdül E. 2006. Ameliyathane dışı anestezi uygulamalarında deneyimlerimiz. Türk Anest Rean Der Derg, 34(3): 169-176.

Jenkins JG, Khan MM. 2003. Anaesthesia for Caesarean section: a survey in a UK region from 1992 to 2002. Anaesthesia, 58(11): 1114-1118.

KHGM. 2017. Kamu hastaneleri genel müdürlüğü; İstatistik, analiz, raporlama ve stratejik yönetim dairesi başkanlığı. 'Her Branşta İlk 100 Hastane' 2017 yllı Ocak-Ekim Dönemi Poliklinik, Yatış, Yoğun Bakım ve Acil Servis İstatistikleri. Ankara.

URL:

https://dosyahastane.saglik.gov.tr/Eklenti/9300,2017-ocakekim-donemi-poliklinik-yatis-ve-yogun-bakim-ve-acil-servisverileri-baglaminda-her-bransta-ilk-100-hastanepdf (access date: December 05, 2017).

Lai HY, Tsai PS, Fan YC, Huang CJ. 2014. Anesthetic practice for Caesarean section and factors influencing anesthesiologists' choice of anesthesia: a population-based study. Acta Anaesthesiol Scand, 58(7): 843-850.

Marcus HE, Behrend A, Schier R. 2011. Anesthesiological management of Caesarean sections: nationwide survey in Germany. Anaesthesist, 60(10): 916-928.

McGoldrick KE. 2008. Anesthesia Considerations for Geriatric Outpatients. In: Silverstein JH, Rooke GA, Reves JG, Mcleskey $\mathrm{CH}$ (eds). Geriatric Anesthesiology. 2nd ed. Springerscience + Business Media, New York, US, pp: 337.

Morgan GE, Mikail MS, Murray MJ. 2002. Postanesthesia Care. In: Morgan GE, Mikail MS, Murray MJ (eds.) Clinical AnesthesiologyLange Medical Books/ McGraw-Hill, New York, US. . 3rd ed., pp. 950.

Odin I, Feiss P. 2005. Low flow and economics of inhalational anaesthesia. Best Pract Res Clin Anaesthesiol, 19(3): 399-413.

Okur O, Telgul ZT, Yeniay O, Direnç KE. 2016. Effect of low flow anesthesia education on short term anesthetic gas consumption. Tepecik Eğit ve Araş Hast Derg, 26(2): 146-150.

Palmer SK. 2009. Anaesthesia care for obstetric patients in the United States. 1st ed. Springer-Verlag, London, UK, pp: 200.

Sabate S, Gomar C, Canet J, Fernandez C, Fernandez M, Fuentes A. 2006. Obstetric anesthesia in Catalonia, Spain. Med Clin (Barc), 126(2): 40-45.

Toker K, Yılmaz AS, Gürkan Y, Baykara N, Canatay H, Özdamar D. 2003. Sezaryen ameliyatlarında anestezi uygulaması, 5 yıllık retrospektif değerlendirme. Türk Anest Rean Cem Mecmuası, 31: 26-30.

Töre G, Gurbet A, Şahin Ş, Türker G, Yavaşçaoğlu, Korkmaz S. 2009. Türkiye'de obstetrik anestezi uygulamalarındaki değişimin değerlendirilmesi. Turk J Anaesth Reanim, 37(2): 86-95.

TARD. 2015. Türk Anesteziyoloji ve Reanimasyon Derneği (TARD) Anestezi uygulama kılavuzları. Ameliyathane dışı anestezi uygulamaları. URL: https://www.tard.org.tr/assets/kilavuz/1.pdf (access date: December 02, 2015). 